\title{
FILM VIEWING PREFERENCES AND IMPACT OF SMARTPHONES: A COMPARATIVE ANALYSIS OF URBAN AND RURAL YOUTH IN DELHI (INDIA)
}

\author{
Divyani Redhu* and Sachin Bharti \\ University School of Mass Communication, Guru Gobind Singh Indraprastha University \\ (GGSIPU), New Delhi, India
}

\begin{abstract}
As per the KPMG India Report 2018, the total revenue of the Indian film industry stands at INR 158.9 billion, which itself tells about the popularity of films among Indian masses. Presently, films are no more limited to the theatres. Rather, the scenario has changed drastically now with smartphones and internet revolutionizing the overall communication and entertainment scenario. The number of smartphone users in India as of 2018 is about 339.95 million as per the Statistics Portal, 2018. As per IAMAI report 2018, India is expected to reach over 500 million internet users by end of 2018. Keeping in mind this rapid penetration of smartphones in India, the aim of researchers is to understand the film viewing preferences of youth in Delhi (Capital of India) vis-à-vis the impact of smartphones. The study would be a comparative analysis of urban and rural youth of Delhi. 2 rural zones and 2 urban zones will be chosen from Delhi and 50 respondents will be chosen from each area in the age bracket of 15-24 years as per the definition of youth by the United Nations. 200 respondents will be chosen in total. The study by the researchers would be quantitative in nature. For the same, a survey would be conducted. The tool of the survey would be questionnaire. The results derived from the study would primarily focus on the difference in the film viewing habits of the youth in urban and rural Delhi (India), the smartphone usage and engagement pattern vis-à-vis film viewing etc.
\end{abstract}

Keywords: Delhi, Film Viewing, India, Smartphone, Youth

\section{Introduction}

"Obviously there is still something unique and inherently appealing about going to the movies, and this is clearly different from other mass media experiences"

\section{- Jovett and Linton}

Waiting for a new film to release, standing in the queues to buy tickets and watching a film on screen is not uncommon to most of us. Rather, it would not be wrong to say that watching films is more like a part of our lives. Going out to watch films, be it with family or even friends is solidly settled in our society and motion pictures have had a significant impact as one of the elements adding to the drastic changes which have occurred around us in the manner we live and furthermore by the way we see our general surroundings.

Not only have films been able to take care of our appetite for entertainment, but, at the same time; they have time and again proven to be potent in mobilizing the thinking amongst the masses for a particular issue, cause etc. It would not be exaggerating to say that it is hard to even consider our society without films.

It was no less than a marvel for the viewers to witness moving images on screen. Undoubtedly, it was the medium of films that made it possible over a century ago, taking into account the advent of cinema. Ever since Lumiere Brothers introduced the world to the magic of cinema, films, motion pictures; the medium has managed 
to enthral its viewers. It is the power of the medium that has the potential to sometimes show the reality on screen, and other times, taking the viewers away from the realities of the mundane daily lives and making them experience the fantasies for the duration of the particular film. The connection that film, as a medium of communication has managed to establish with the viewers is certainly very well established and concrete.

Taking into account the Indian cinema, the industry as a whole has had a quite notable history and at the present, it's enjoying being one of the largest film producing industries within the world. The Indian film industry annually produces over 1000 films, which is a huge figure in itself. However, it is not merely the sheer number of films produced within India that makes it worth noticing, but, the dedication, passion and bond that the viewers share with Cinema here is also a delight to even witness. Films from the beginning became one of the most popular mode of expressions, primarily because it was the first medium to combine audio and video together. Films, certainly are a potent medium of entertainment, but, at the same time, they're additionally thought of as mirror of society. In a country like India, this medium of mass communication is incredibly potent since its inception within the mass media vehicle and time to time, it self-addressed several social, political and other vital issues through its varied themes.

As per the KPMG in India analysis, 2018; the overall size of the film industry was said to be an astonishing 158.9 billion. As per the projections of the same report, the film industry is expected to reach 228.8 billion by the year 2023. The figures are sufficient proof about the humongous popularity of films, particularly in India. Regardless of the gender, age, religion, region and other all such different factors, films have time and again managed to gain everyone's attention. It would not be wrong to say that films have a language of their own, which necessarily do not always need words and vocals to communicate. The association is much more rooted with the viewers, which most of the times makes it possible for them to understand what's being portrayed, even in the absence of words. Such is the power of films.

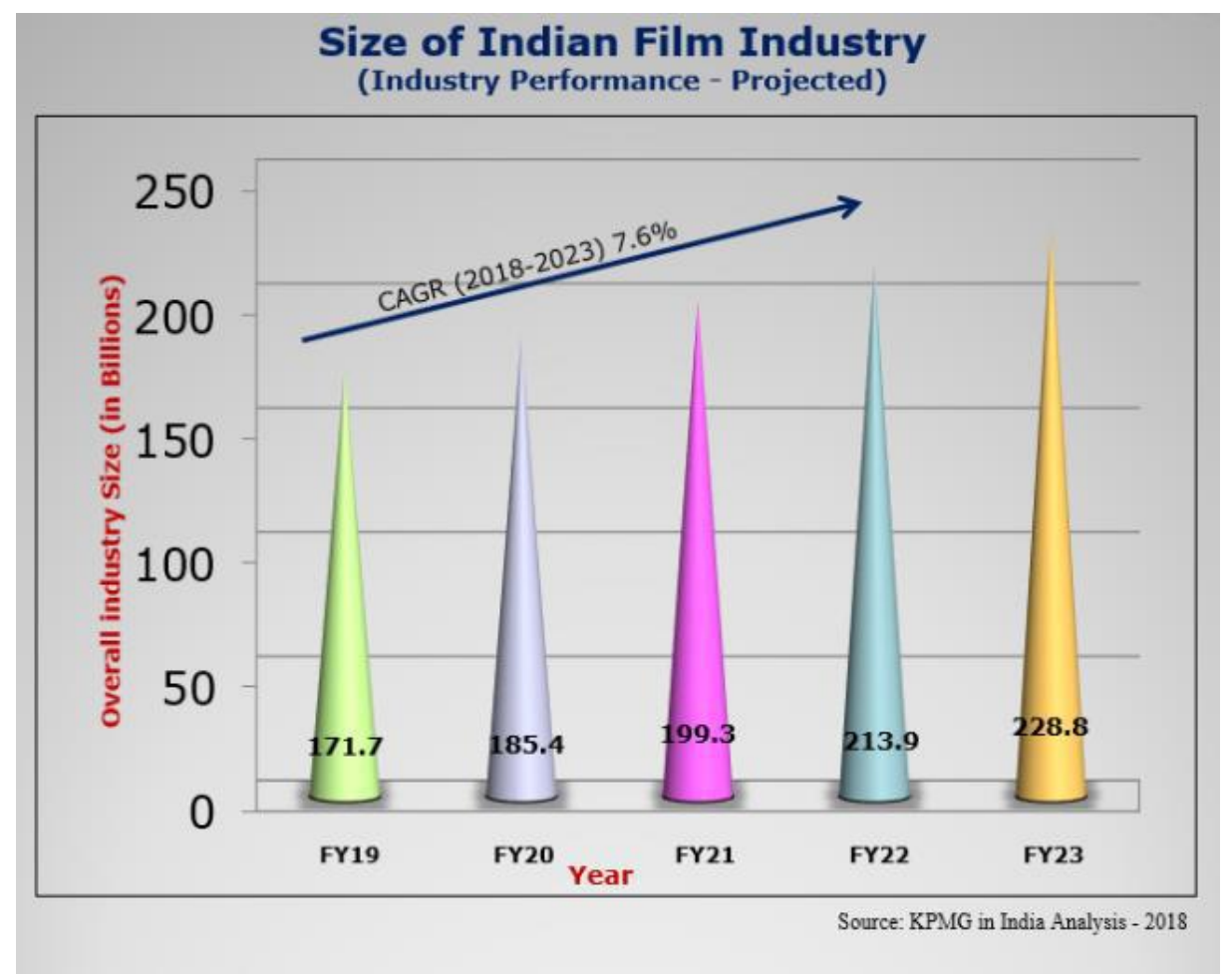

Figure 1:The Industry Projections as per the KPMG in India Analysis, 2018 predicts the overall industry size of Indian film industry to reach 228.8 billion by the year 2023

As already mentioned, films that we see today have developed over a century, and not simply that, they have had the option to catch the brains just as hearts of the spectators, especially the youth, for whom film is a 
medium that has sometimes worked as a mirror for them, and sometimes as a legacy which has been passed on since generations, on screen. Films figured out how to take into account the eyes and ears long time ago, which no other medium could do as such well.

\section{The Evolution of Films}

The journey of Indian cinema that began from its primitive stage of flashing the stationary photographs with poor sound to the subtle and technologically advanced business of these days, is certainly a long one. The business that took its opening over a century ago with the silent, short films and plays, has currently reached the stage where it stands head high with any of the existing film industries around the globe. The word 'Bollywood', used for notably the Hindi industry has nearly become substitutable to exotic locations and delightful stars, a string of songs and dance numbers. But, the Indian industry has not perpetually been of this fashion.

Talking into account the changes within the films these days, they embody each - the creative as well as the technological changes. Also, what must be noted is the fact that today, with the tremendous advancements within the technology, films are not simply restricted to the theatre screen. Laptops/desktops, smartphones etc. all have currently become the mediums which offer the option of viewing films at one's ease and convenience. It would not be wrong to mention that online media and the advent of internet has definitely contend an important role in making this happen.

Film intake has changed dramatically in the past few years. The upward push of the multiplex has re-established the public experience of cinema viewing. At the same time, film viewing has grown exponentially in domestic and mobile spheres, pushed by means of increasingly flexible access to content and the range of screens that can substitute the theatres, if not necessarily can replace them. From laptops to smartphones, today films have forayed into all screen sizes. The same transition can either be seen as a boon or bane for the industry as a whole.

But, over a century later, one issue that has not modified even these days is the undeniable fact that films have a long-lasting impression on the minds and hearts of the viewers. What we all as viewers see on the screen typically gets inscribed in our minds as a validation of truth. Thus, being such an impactful medium, that is looked upon with vast commendation by the viewers, films certainly have a large responsibility on them.

\section{Statistics}

The number of internet users in India is estimated to reach around 500 million by the end of 2019 as per the Internet and Mobile Association of India (IAMAI) report, which itself clears the immense potential that online media holds. The surplus internet data available today at highly affordable prices is becoming a threat to many traditional media. At the end of December 2017, India had 481 million users, growing 11.34\% from 2016. Taking into account the number of internet users in the Asia Pacific region as of January 2019, India accounted for 560 million internet users, standing only behind China which had 802 million internet users. 


\section{Number of Internet Users in Select Asia-Pacific Countries \\ (January 2019)}

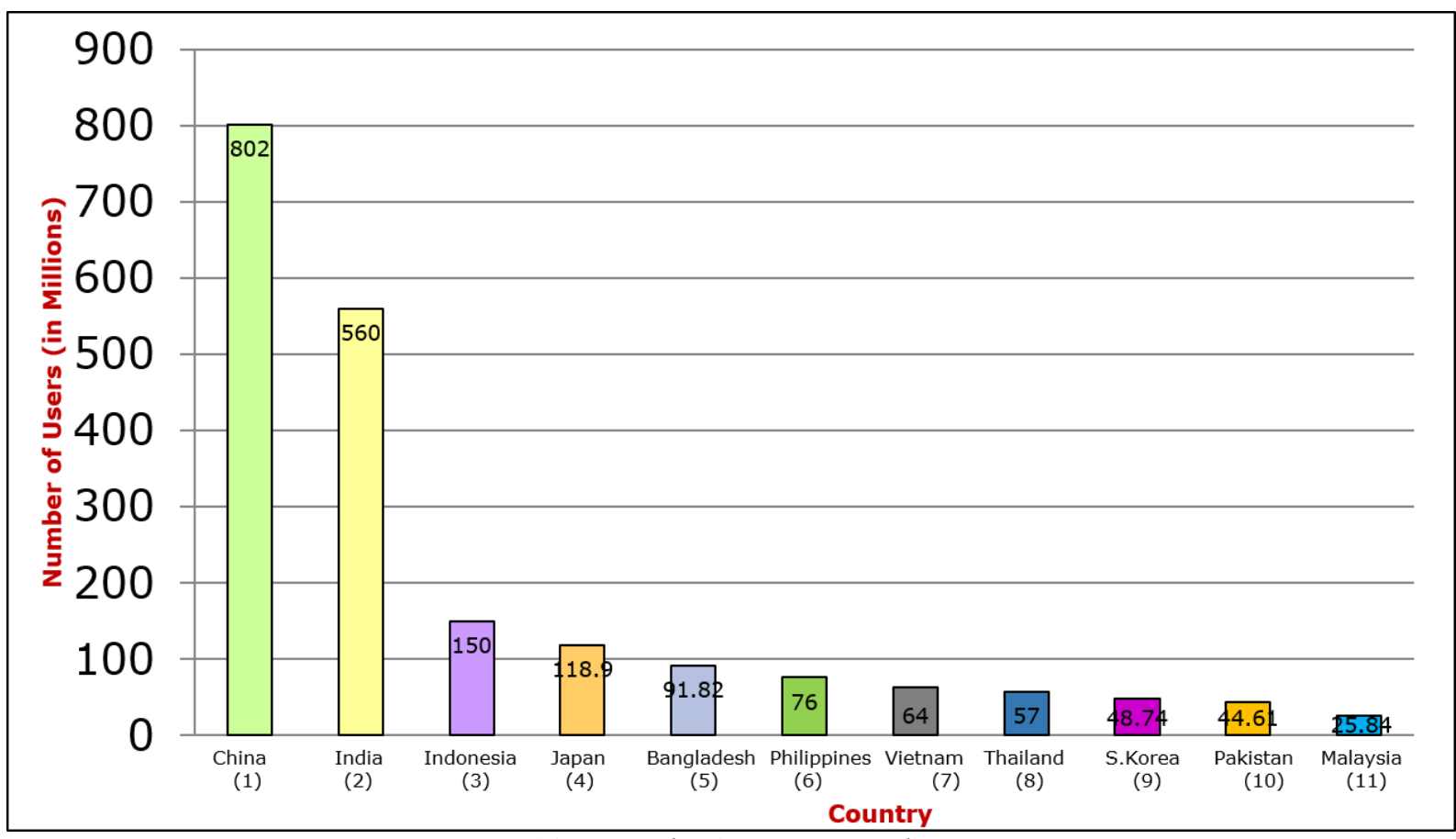

(Source: The Statistics Portal)

Figure 2: Number of Internet Users in Asia - Pacific Region (in million)

\section{Literature Review}

Olivia Chausson of Cambridge University in her paper titled: 'Assessing the Impact of Gender and Personality on Film preferences' examined the impact of gender and Big Five personality factors (Openness, Conscientiousness, Extraversion, Agreeableness and Neuroticism) on visual media preferences (for comedy, horror, action, romance and fantasy film genres) using data collected by Stillwell's (2007) myPersonality application on Facebook; and focused on a sub-sample of British residents aged 16-25 ( $\mathrm{n}=29,197)$. It was confirmed in her study that females prefer romantic films, whereas males favour action films. Also, females scored better on neuroticism and agreeableness than men. Individuals scoring more on the measurement of openness were much more likely to pick comedy and fantasy movies than romantic films. Conscientious people were found to be more willing to enjoy action and romance genres. Individuals scoring more on neuroticism tended to prefer romantic films. Finally, considerable interactions were mentioned among gender and openness in regards to preferences for comedy, action and romance genres.

In the research paper by Saham Barzaa and Mehran Memarib titled: 'Movie Genre Preference and Culture', the role of cultural factors on the learners'preferences when exposed to target and foreign culture was investigated. The results of the above mentioned study indicated that thinking about beginners' film style desire cannot constantly bring about higher overall performance; when cultural literacy is required, their preference might shift to extra comprehensible contexts/ movies.

Movies provide natural and proper context for practice of language. In this regard, the character of movie and its style may have sizable effect on the degree of learners' comprehension. Genres have sizeable function in media research. Some researches have been targeted on the language competencies when it comes to characteristic films' genre. These researches have targeted on exclusive angles and feature pondered distinct perspectives (Hatakeyama, 2011). 
In the article by Bhawna Singh titled: 'The movie viewing experience of an average Indian cinemagoer', it was mentioned that YouGov survey conducted among over 1,000 respondents in India, shows that every 1 in 6 cinemagoers watches a movie every week. Cine buffs are visiting theatres $44 \%$ more often than they did last year, and intend to do so even more in the coming year. $72 \%$ people enjoy the ambience and prefer watching films on the big screen, although $31 \%$ feel it is very expensive and prefer streaming films online instead. Indians love their movies no matter what the genre, be it comedy, action or romance. Over $60 \%$ people linked their movie outings to social engagements with family \& friends. The urban audience is evolving with over $50 \%$ cinema enthusiasts basing their movie viewing decision on the story and star cast of the film rather than the publicity generated around it.

In an article by Emily Dyess titled: 'Infographic: The Psychology of Movie Tastes and Preferences', it was mentioned that Americans devote over 38 hours per week, or 55\% of the time they are awake, to watching TV and movies. Both regular and occasional film viewers affirm that films are a pivotal part of their lives.

In an article by Aleit Veenstra titled: 'Young film audiences: preferences and practices', a research project Screen(ing) Audiences was mentioned. The study is grounded in a representative sample of 1,015 respondents aged 16-18 who were asked about their film viewing practices. The respondents were all based in Flanders, the Dutch-speaking region of Belgium. The results concluded that young people enjoy watching film, and are frequent film viewers too. Nine out of every ten 16-18 year-olds saw at least one film in the week before completing the questionnaire - with an average of 2.5 films per week. Moreover, watching film is loved: only $3 \%$ do not enjoy watching film. We therefore take the practice of watching film as a starting point to question contemporary media consumption possibilities in relation to different types of screens (access) and films of different geographical origins (content).

\section{Discussing the Objectives and Methodology}

By using survey method, a study was conducted by the researchers for analysing the film viewing preferences and impact of smartphones on youth in Delhi. The study conducted was a comparative analysis between the Urban and Rural youth in Delhi.

The United Nations, for statistical purposes, defines 'youth', as those persons between the ages of 15 and 24 years. Thus, keeping the same in mind and taking into account the purpose of the study, i.e. to do a comparative analysis of the Urban and Rural zones of Delhi, a study was conducted among the respondents of above mentioned age group. The tool of the survey was questionnaire. Number of respondents was 200. Out of the 11 districts in Delhi, 2 rural zones (Kanjhawala - North West Delhi, Chhawla - South West Delhi) and 2 urban zones (Rohini - North West Delhi, Dwarka - South West Delhi) were chosen by the researchers keeping in mind the accessibility factor. 50 respondents from each of the 4 areas were chosen from the above mentioned age bracket. 


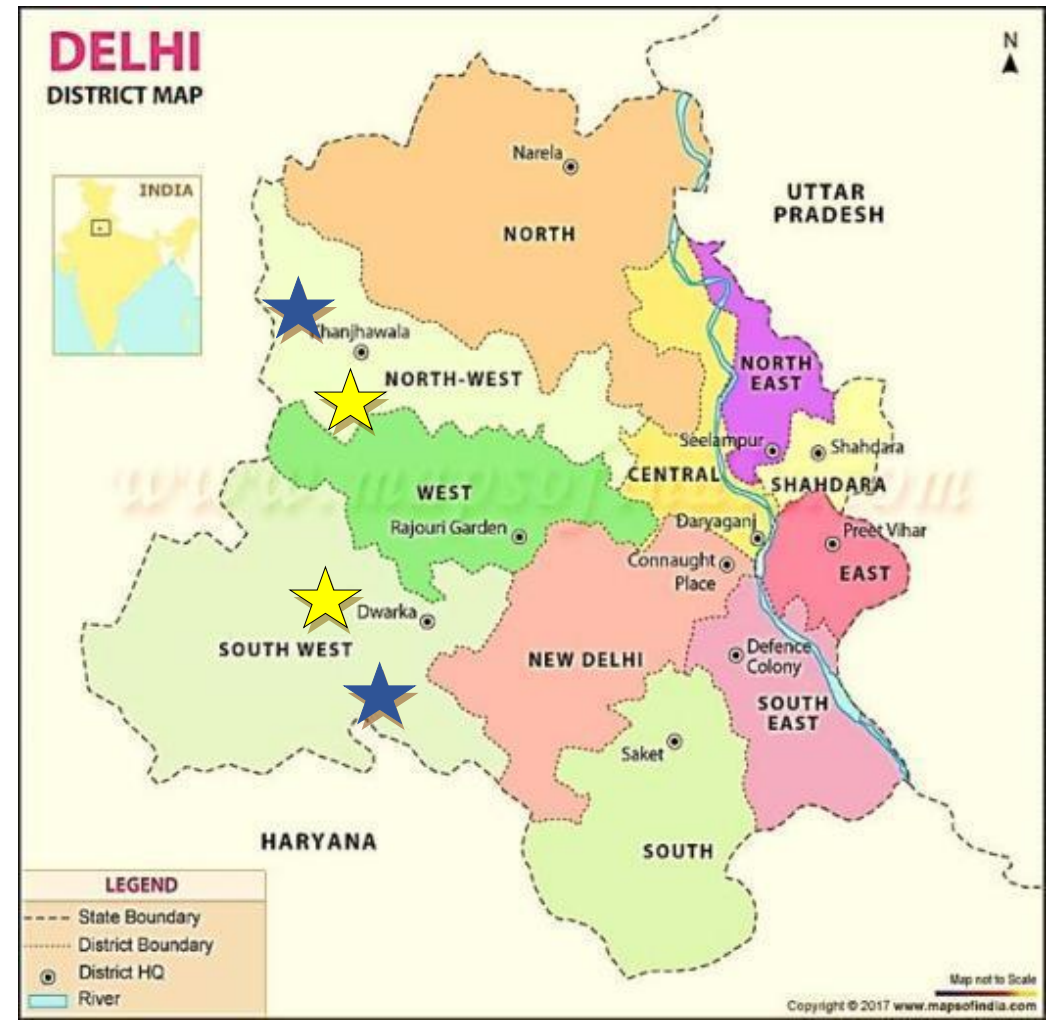

Source: Google images

(https://www.google.com/search?q=delhi+map\&source=lnms\&tbm=isch\&sa=X\&ved=0ahUK Ewj147reo5bgAhWHM48KHW xClAQ AUIDygC\&biw=1536\&bih=747\#imgrc=EbA 79zJ C-0EM:\&spf=1548877890360)

Figure 3 Map of Delhi, India. The stars mark the areas that were chosen for the purpose of study out of the 11 districts in Delhi. The blue stars are the locations of the rural zones and yellow stars are the locations of the urban zones

The research paper on the topic has been written with the following objectives in mind:

- $\quad$ To identify the film viewing preferences of youth in Delhi

- To identify the engagement of youth in Delhi on smartphones for film viewing

- To compare the film viewing preference of youth in Urban and Rural zones of Delhi

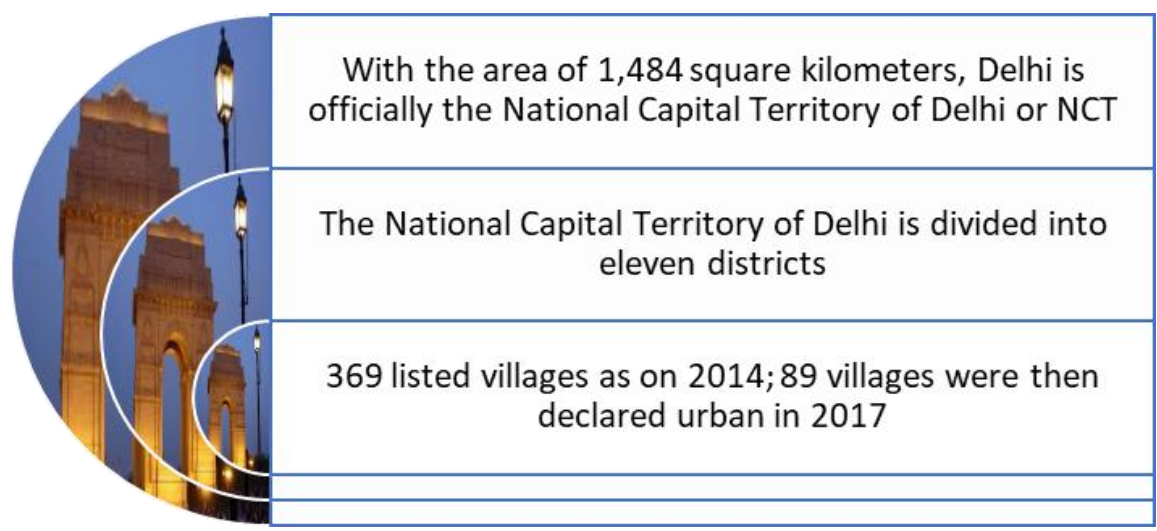

Figure 4: Facts about Delhi (Source: http://www.delhi.gov.in/DoIT/DoIT_Planning.pdf) 


\section{Key Findings}

Out of the 200 respondents, the number of males was 84 and the female respondents were 116. Also, the school going respondents were 48, college going were 88 while the working /office goers were 64 respectively.

When the respondents were asked about watching films, out of 200 respondents, all the respondents in both Urban and Rural zones replied in affirmative. Also, a substantial majority of 84 respondents said that their frequency of watching films is weekly, followed by fortnightly, which was chosen by 53 respondents.

\begin{tabular}{|l|l|l|l|}
\hline Frequency & Number & \multicolumn{1}{|c|}{ Gender } & Area \\
\hline Weekly & 84 & $\mathrm{M}-43, \mathrm{~F}-41$ & $\mathrm{R}-64, \mathrm{U}-20$ \\
\hline Fortnightly & 53 & $\mathrm{M}-25, \mathrm{~F}-28$ & $\mathrm{R}-35, \mathrm{U}-18$ \\
\hline Monthly & 44 & $\mathrm{M}-18, \mathrm{~F}-26$ & $\mathrm{R}-18, \mathrm{U}-26$ \\
\hline $\begin{array}{l}\text { Every 6 } \\
\text { Months }\end{array}$ & 16 & $\mathrm{M}-12, \mathrm{~F}-4$ & $\mathrm{R}-5, \mathrm{U}-11$ \\
\hline Annually & 3 & $\mathrm{M}-3, \mathrm{~F}-0$ & $\mathrm{R}-2, \mathrm{U}-1$ \\
\hline Never & 0 & $\mathrm{M}-0, \mathrm{~F}-0$ & $\mathrm{R}-0, \mathrm{U}-0$ \\
\hline
\end{tabular}

(R-Rural, U-Urban)

Figure 5: Frequency of Film Viewing

When asked about the preferred genre of watching films, action was the most preferred genre of watching films which was chosen by 72 respondents in total, followed by comedy with 64 respondents. Action was chosen by 54 females (R-28, U-26) and 18 males. Comedy was chosen by 42 males (R-24, U-18) and 22 females. Horror films was chosen by a majority of 22 females (R-16, U-6) out of 27.

Smartphone as the most preferred medium was chosen by a majority of 76 respondents. This was followed by T.V., chosen by 46 . Last but not the least, theatre was chosen by a total of 34 respondents.

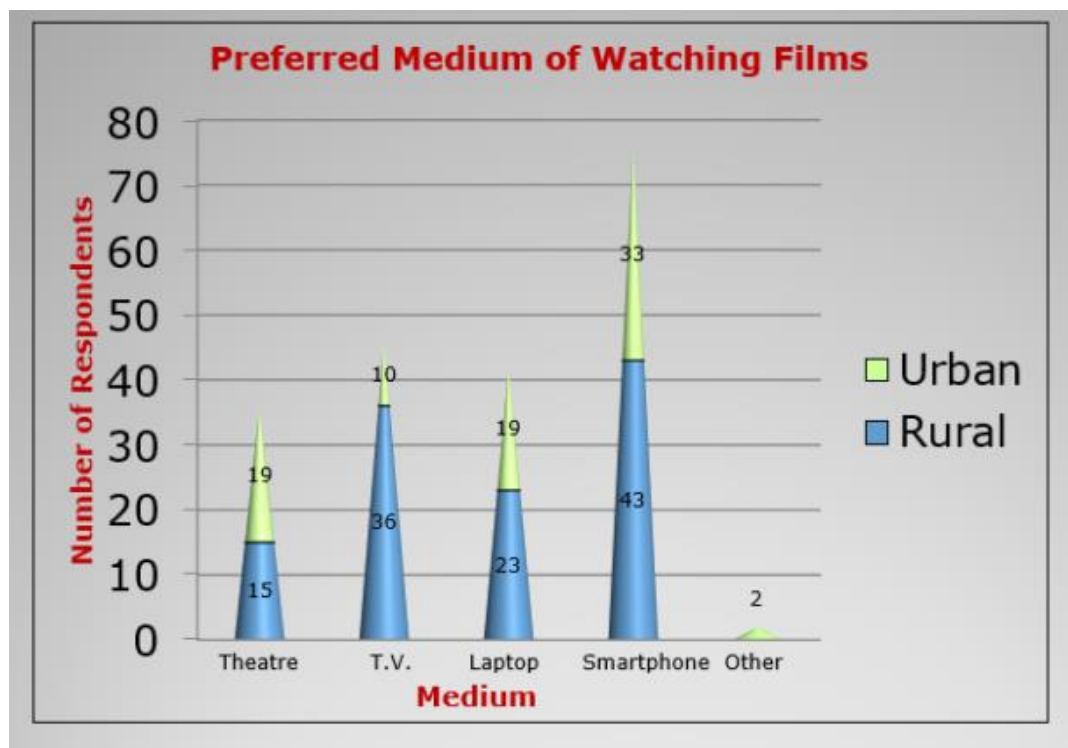

Figure 6: Comparative graph of the preferred medium of watching films

Further, 186 respondents (M-94, F-92) out of the total 200 respondents affirmed to have smartphones and 89 out of the same were from the rural zones. When the respondents were asked about having internet access, all the respondents affirmed to have internet access. 
Smartphone emerged as the preffered medium to access internet by a majority of 122 respondents (R-64, U-58). Out of 122, school going were 9, college going were 58 and working respondents were 55. The remaining 78 respondents chose laptop/desktop as their preferred medium to access internet.

\begin{tabular}{|l|l|l|l|}
\hline $\begin{array}{l}\text { Frequency of Watching } \\
\text { Films on Smartphone }\end{array}$ & Number & \multicolumn{1}{|c|}{ Gender } & \multicolumn{1}{c|}{ Area } \\
\hline Everyday & 11 & $\mathrm{M}-8, \mathrm{~F}-3$ & $\mathrm{R}-9, \mathrm{U}-2$ \\
\hline Twice/Thrice a Week & 72 & $\mathrm{M}-43, \mathrm{~F}-29$ & $\mathrm{R}-45, \mathrm{U}-72$ \\
\hline Once a Week & 36 & $\mathrm{M}-8, \mathrm{~F}-28$ & $\mathrm{R}-45, \mathrm{U}-72$ \\
\hline Fortnightly & 28 & $\mathrm{M}-6, \mathrm{~F}-22$ & $\mathrm{R}-21, \mathrm{U}-7$ \\
\hline Monthly & 50 & $\mathrm{M}-16, \mathrm{~F}-34$ & $\mathrm{R}-28, \mathrm{U}-22$ \\
\hline Every 6 Months & 3 & $\mathrm{M}-2, \mathrm{~F}-1$ & $\mathrm{R}-0, \mathrm{U}-3$ \\
\hline Annually & 0 & $\mathrm{M}-0, \mathrm{~F}-0$ & $\mathrm{R}-0, \mathrm{U}-0$ \\
\hline Never & 0 & $\mathrm{M}-0, \mathrm{~F}-0$ & $\mathrm{R}-0, \mathrm{U}-0$ \\
\hline
\end{tabular}

Figure 7 :Frequency of Watching Films on Smartphones

Small Screen Size was chosen by a majority of 126 respondents (R-41, U-85) as their reason for disliking watching films on smartphone. Lack of ambience was chosen by 54 (R-21, U-33). The other options were: lack of concentration (9), low audio quality (11).

On being asked about the means of watching films on smartphone, 86 respondents out of 200 said that they downloaded the films from internet and saw the same, online streaming was chosen by 76 females (R-34, U-42). However, offline viewing was chosen by 38 males (R-24, U-14).

When the respondents were asked about their preference of watching films on smartphones than theatres; out of 98 respondents saying yes, 69 were from Rural and rest 29 were from Urban zones in Delhi. Out of 81 saying no, a majority of 54 respondents were working and 21 were college going students. However, only 6 were school going students.

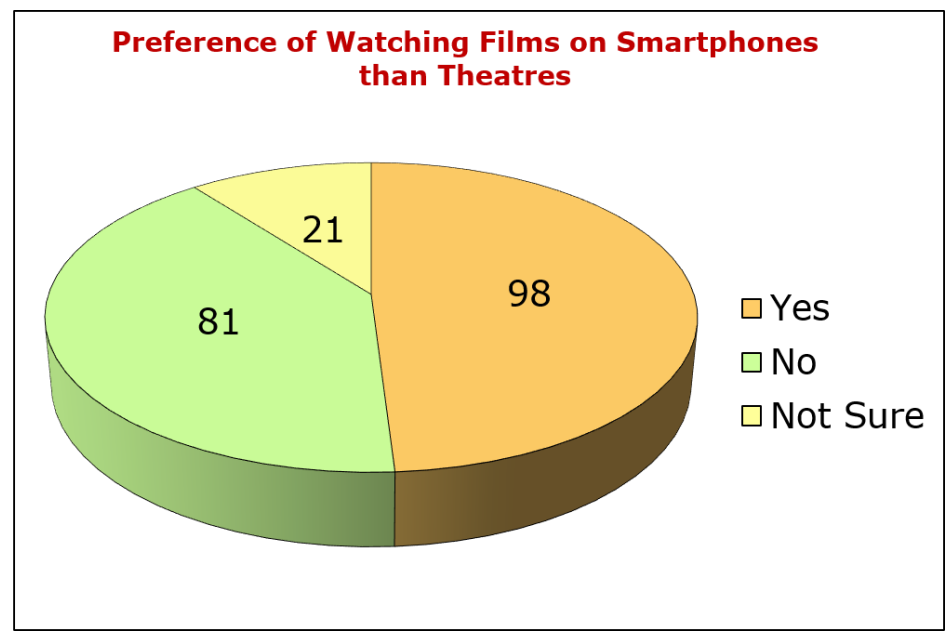

Figure 8: Pie Chart Showing the Preference of Watching Films on Smartphones than on Theatres

When asked whether the respondents thought that popularity of smartphones could replace theatres, a majority of 96 respondents surprisingly chose yes (R-63, U-33) while No was chosen by 42 respondents (R-17, U-25). Further, about being asked about the compromised pleasure of film viewing on smartphones, Yes was chosen by 
54 respondents (R-11, U-43) and a majority of 146 respondents chose No as the option (R-95, U-51). This itself tells about the increasing popularity of smartphones for film viewing.

\section{Conclusion}

With the help of the close ended questionnaire that was given to the respondents, the researchers were able to gather information about aspects like the preferred medium of watching films by the respondents, frequency of watching films, their usage of smartphones vis-à-vis film viewing, etc. Overall, with regards to the information as received by 200 respondents from specifically the youth of urban and rural zones of Delhi, it can easily be said that the majority of youth in Delhi is regular film viewers. However, the small sample size is certainly a limitation of the study.

Strictly on the basis of the responses by 200 respondents, it would not be wrong to say that the most dedicated film viewers are from the rural zones. Smartphone was found as the preferred device of film viewing by the rural respondents. However, theatres were more popular among the urban youth. Also, as per the study, smartphones could replace the popularity of theatres in future.

In addition, it needs to be taken into account that no striking difference was found out by the researchers on the basis of gender (male and female) even in the rural zones of Delhi. However, the difference that stood out most was in the case of $15-17$ years age group. It was the age group of $15-17$ years that were the majority respondents in case of responding about not having a smartphone, the group that majorly accessed internet on laptop/desktop and surprisingly, were the least dedicated film viewers.

To conclude, it cannot be negated that films are hugely popular among the youth in Delhi and also, in a very short span of time, the market that smartphone and internet have carved for themselves is huge and the youth has a major role to play in the same. With mobile network becoming more accessible, and Internet Service Providers offering unlimited data plans at the price of peanuts, online engagement is booming than ever in India.

Although, the findings of the present study must be considered within its limitations due to the small sample size and use of only close ended questionnaires. For future research in a related area, the area of research may be expanded beyond only Delhi, with the usage of interviews and focus group discussions to dwell deeper in the subject.

\section{References}

(PDF) Cinema-Going and Film-Viewing Habits: A Case Study ... (n.d.). Retrieved from https://www.researchgate.net/publication/272158566_Cinema-Going_and_FilmViewing_Habits_A_Case_Study_of_Film-Viewers_in_Kuantan

Aveyard, K. (n.d.). Film consumption in the 21st century: Engaging with non-theatrical viewing - Karina Aveyard, 2016. Retrieved from https://journals.sagepub.com/doi/abs/10.1177/1329878X16642851

Barza, S., \& Memari, M. (2014). Movie Genre Preference and Culture. Procedia - Social and Behavioral Sciences, 98, 363-368. doi:10.1016/j.sbspro.2014.03.427

Bharti, S., \& Redhu, D. (2015). Most Potent Tool of New Media: The Smartphones (An Analysis). IJCD. ISSN 2231-2498, 4 and 5.

Chausson, O. (n.d.). Assessing The Impact Of Gender And Personality On Film Preferences [Scholarly project]. Retrieved from https://pdfs.semanticscholar.org/682f/92a3deedbed883b7fb7faac0f4f29fa46877.pdf

Dodge, A. (2018, January 04). How Technology Continues to Revolutionize the Film Industry. Retrieved from https://blog.ozobot.com/2018/01/04/how-technology-continues-to-revolutionize-the-film-industry/

Dyess, E. (n.d.). Infographic: The Psychology of Movie Tastes and Preferences. Retrieved from http://blog.motivemetrics.com/the-psychology-of-movie-tastes-and-preferences

Hoffmann, Dagmar, Schwender, \& Clemens. (2007, November 20). Biographical functions of cinema and film preferences among older German adults: A representative quantitative survey, Communication \& Medicine. 
Retrieved from https://www.deepdyve.com/lp/de-gruyter/biographical-functions-of-cinema-and-filmpreferences-among-older-mliJPUUgGV

Kaufman, J. C., \& Simonton, D. K. (2014). The social science of cinema. New York: Oxford University Press.

Manning, E. (2017, January 25). Technology Has Changed The Way We Watch Film and TV. Retrieved from https://yongemag.com/technology-has-changed-the-way-we-watch-film-and-tv-196e281ad6ac

Redhu, D. (2019). Alternate Film Streaming Platforms and Youth Preferences in Delhi - NCR: An Analysis. In World Cinema and Alternate Networks (pp. 180-192). New Delhi, Delhi: Kanishka.

Singh, B. (n.d.). The movie viewing experience of an average Indian cinemagoer. Retrieved from https://in.yougov.com/en-hi/news/2018/07/20/movie-viewing-experience-average-indian-cinemagoer/

Veenstra, A. (n.d.). Young film audiences: Preferences and practices. Retrieved from https://cineuropa.org/en/newsdetail/319036/ 
Appendix

Name:

Age:

Gender: Male

Female

Transgender

Address:

Phone number:

Occupation:

Email id:

Kindly go through the following questions. I would be highly obliged to know your valuable answers

Question 1: Do you watch films?

Yes $\square \quad$ No $\square$

Question 2: How often do you watch films?

Weekly $\square \quad$ Fortnightly $\square \quad$ Monthly $\square \quad$ Every 6 Months

Annually

Never

Question 3: Which type of films do you prefer watching the most?

Action

Romantic

Comedy

Horror

Any other

Question 4: Which is your most preferred medium of watching films?

Theatre

T.V.

Laptop/Desktop

Smartphone

Any other

Question 5: Do you have your own smartphone?

Yes

$$
\text { No }
$$

Question 6: Do you have internet access?

Yes

No

Question 7: Which is your preferred medium of accessing internet?

Laptop/Desktop Smartphone

Any other (like tablet etc.)

Question 8: How often do you watch films on your smartphones?

Everyday

Monthly
Twice/thrice a Week

Every 6 Months
Once a Week

Annually
Fortnightly

Never

Question 9: Do you like watching films on your smartphones?

Yes

No

Not Sure 
Question 10: What do you dislike in watching films on smartphones?

Lack of the ambience

Small screen

Lack of concentration

Low audio quality

Any other

Question 11: How do you watch films on smartphones?

Online Streaming Channels (like Amazon Prime, Netflix etc.)

Download from

internet

Watch online without downloading (like Youtube/any other sites)

Borrow from others (Like bluetooth etc.)

Any other

Question 12: Do you prefer watching films on smartphones over theatres?

Yes

No

Not Sure

Question 13: Why do you like watching films on smartphones?

It is so because watching films on smartphones is:

Inexpensive $\square \quad$ No travelling is needed $\square \quad$ Offers more choice

Convenience $\square$ Any other

Question 14: Do you think that the popularity of smartphones could ever replace theatres/ multiplexes in future?

Yes $\square \quad$ No $\square \quad$ May be $\square \quad$ Don't know

Question 15: Do you think that the pleasure of watching a film is compromised while seeing it on smartphone?

No

May be

Don't know

Thanks a lot for giving your valuable time! 